\title{
Numerical Analysis of the Soil Deformation Caused by Tunneling under Vehicle Loads in the Coastal Reclamation Area
}

\author{
Baoping Zou, ${ }^{1,2}$ Jianxiu Wang, ${ }^{2,3}$ Qian Tian, ${ }^{4}$ Wei Guo, ${ }^{4}$ Jianhui Yang, \\ Jue Yi, ${ }^{5}$ and Zhanyou Lou ${ }^{1}$ \\ ${ }^{1}$ School of Civil Engineering and Architecture, Zhejiang University of Science and Technology, Hangzhou 310023, China \\ ${ }^{2}$ Department of Geotechnical Engineering, Tongji University, Shanghai 200092, China \\ ${ }^{3}$ Key Laboratory of Geotechnical and Underground Engineering of Ministry of Education, Tongji University, Shanghai 200092, China \\ ${ }^{4}$ School of Civil and Environmental Engineering, Nanyang Technological University, Nanyang Avenue, Singapore 639798 \\ ${ }^{5}$ China Tunnel Construction Co. Ltd., Guangzhou, Guangdong 510635, China
}

Correspondence should be addressed to Baoping Zou; zoubp@zust.edu.cn

Received 26 December 2014; Revised 22 February 2015; Accepted 23 February 2015

Academic Editor: Giovanni Garcea

Copyright (C) 2015 Baoping Zou et al. This is an open access article distributed under the Creative Commons Attribution License, which permits unrestricted use, distribution, and reproduction in any medium, provided the original work is properly cited.

\begin{abstract}
Prediction of tunneling induced soil deformation is an important issue in the design of tunnels constructed in the densely populated urban areas. In this paper, commercial FEM software 3D ABAQUS is adopted to simulate the behavior of soil caused by tunneling under vehicle loads in the coastal reclamation area. A field case study was also carried out to verify the accuracy of the proposed model. A good agreement was achieved. It is also found from the studies that the areas affected by soil deformation can be classified into four zones: the key disturbed zone, the secondary disturbed zone, the general disturbed zone, and minor-disturbed zone. The maximum soil deformation occurs on side of the longitudinal medial axis of the tunnel. The shape of the settlement curve is almost the same as that of the normal distribution curve. The soil deformation in the action zone of vehicle load is greater than that of the nonaction zone of vehicle load.
\end{abstract}

\section{Introduction}

The development of the subway system is one of the primary approaches to solve the problem of lacking of space and resource, as well as improving the efficiency of urban land usage and urban center density mitigation. With the increase of technology development on boring machine, tunneling has become one of the major methods for subway construction. During urban tunneling, the tunnel is often required to be constructed under existing structures, such as expressway, railway, sewerage, power transmission tunnels, communication, and other subsurface lifelines [1]. In such situations, soil deformation caused by tunneling may inevitably affect the adjacent structures by generating additional displacements and stresses $[2,3]$.

Over the last few decades, many approaches, that is, empirical formulas, theoretical analyses, model tests, artificial neural networks and expert intelligent forecasting systems, and numerical simulations, have been performed to investigate the soil deformation with tunneling. Among these methods, the empirical formula method [4-7] features a clear concept, simple calculation, and ease of use. To a certain extent, it reflects the effect of ground settlement on geological conditions, such as formation, tunnel depth, and excavation diameter. However, the empirical formula method cannot accurately forecast the range of ground settlement as it can only take into account few soil parameters and simple geological conditions. The theoretical analysis method [8-11] has the advantages of low computational complexity and high precision, but it is hard to determine precisely the boundary conditions in a complex $3 \mathrm{D}$ space especially for geotechnical engineering applications. The model test method $[12,13]$ could more accurately model the influence of the construction factors on ground settlement. Nevertheless, it is costly, is complex, and suffers from poor controllability. The construction parameters are used merely as a reference 


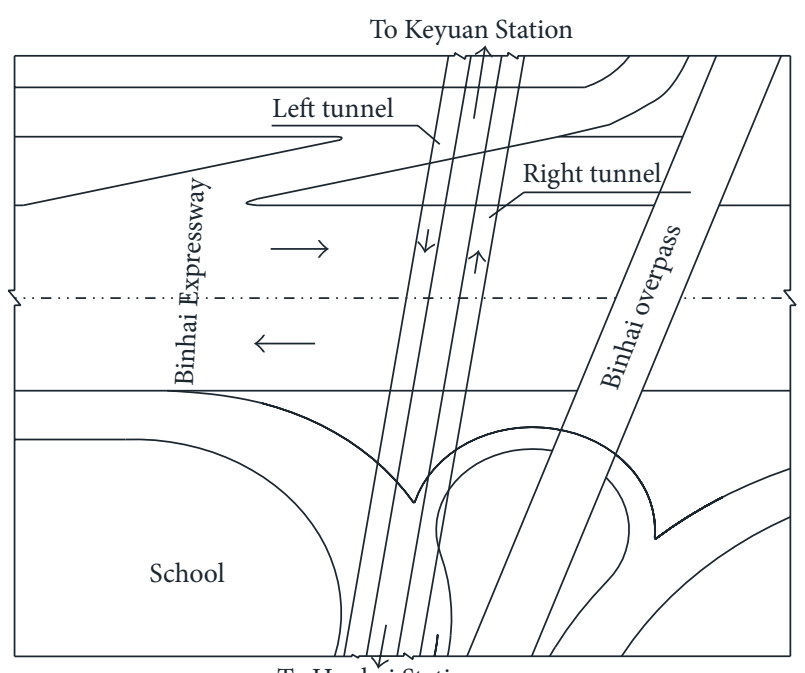

To Houhai Station

FIgURE 1: Layout of the project.

for theoretical analysis and field monitoring. The artificial neural network and expert intelligent forecasting system [1419] have high nonlinear mapping capability, but they need substantial large amount of in situ monitoring data and errors in knowledge acquisition, parallel inference, adaptive learning, associative inference, and easily occurred fault tolerance.

The numerical simulations [20-26] have the advantage of considering different influencing parameters and boundary conditions. For the simulation of the behavior of soil caused by tunneling in the coastal reclamation area, most of the researches in art are based on 2D simulations and few of them on full 3D modeling [1]. Furthermore, the studies on tunneling analysis were focusing on the assessment of the ground surface settlement except little of them which start to pay attention to the interaction between tunneling and existing adjacent structures such as bridges, pile-supported buildings, twin tunnels. Even little research work has been carried out on the interaction between shield tunnels under vehicle loads and soil deformation in a coastal reclamation area.

In this paper, a 3D numerical investigation on soil deformation caused by tunneling under vehicle loads in the coastal reclamation area is carried out. The study aims to identify the fundamental deformation mechanisms involved in the responses of the tunneling under vehicle loads, in terms of the soil deformation and types of vehicles. A field case study was also carried out to verify the accuracy of the proposed model.

\section{Description of the Project}

2.1. Characteristics of the Tunnel. A typical tunnel section was adopted for the Shenzhen Metro Line 2 construction project. This tunnel was constructed from Houhai Station to Keyuan Station with the earth pressure balance (EPB) shield machine. The EPB shield machine has an external diameter of $6.28 \mathrm{~m}$ and a length of $7.58 \mathrm{~m}$. It was launched from the departure shaft at Houhai Station and finally reached the arrival shaft at Keyuan Station (Figure 1). The tunnel of this section is

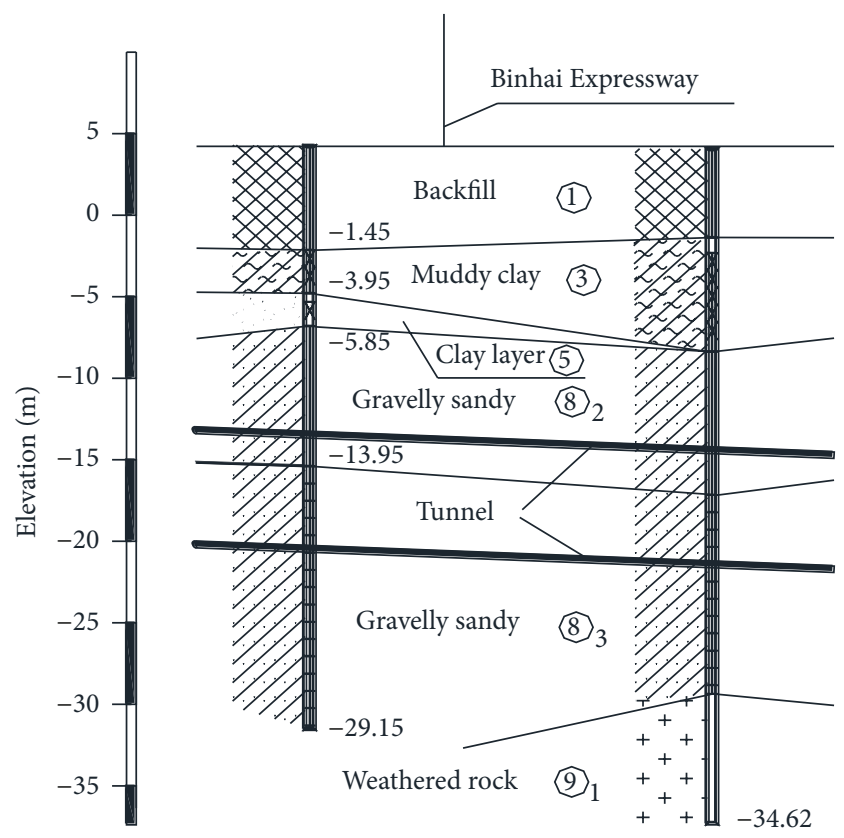

FIGURE 2: Engineering geology profile.

$2473.708 \mathrm{~m}$ long, with its mileage from YDK9 + 629.740 to YDK10 + 850.200. At each section, six prefabricated concrete sections were placed to form the tunnel lining and joined with bolts in the longitudinal and circumferential direction. The size of each ring of lining is $0.30 \mathrm{~m}$ thick and $1.5 \mathrm{~m}$ wide. The concrete tunnel lining has Young's modulus of $34500 \mathrm{MPa}$ and Poisson's ratio of 0.167 .

2.2. Characteristics of the Soil. A typical ground condition encountered in the Shenzhen metropolitan area was also considered in this study. Shenzhen lies in the Pearl River Delta plain and has a complex geology of a mostly watery and weak stratum. The soil profile of the city is characterized by high sensitivity, high water content, and high changeability. Moreover, as numerous coastal reclamation projects have been carried out in Shenzhen recently, the city is now confronting with special engineering problems that differ from those in Guangzhou and Shanghai during subway construction in soft soil. Such problems include the following: (1) the soil layer is still under consolidation as the coastal reclamation project was just finished in 2002; (2) the groundwater table is affected by the flood and ebb tides obviously due to the strong hydraulic connection between groundwater and seawater; and (3) there is a great amount of rubble (gravel) with large diameters in the back fill.

A typical geotechnical section is given in Figure 2. The site was reclaimed from the sea by a soft foundation treatment in 2002. In this area, the top layers mainly consist of backfill and muddy clay. A shallow backfill layer with a thickness of $6.0 \mathrm{~m}$ is present on top of the muddy clay layer which has a depth of up to $4.0 \mathrm{~m}$. Under the muddy clay layer, there is a thin layer of clay. The layers under this second clay layer are the gravelly sand layer and the weathered rock layer, and the tunnel is mainly embedded in the gravelly sand layer. The groundwater 


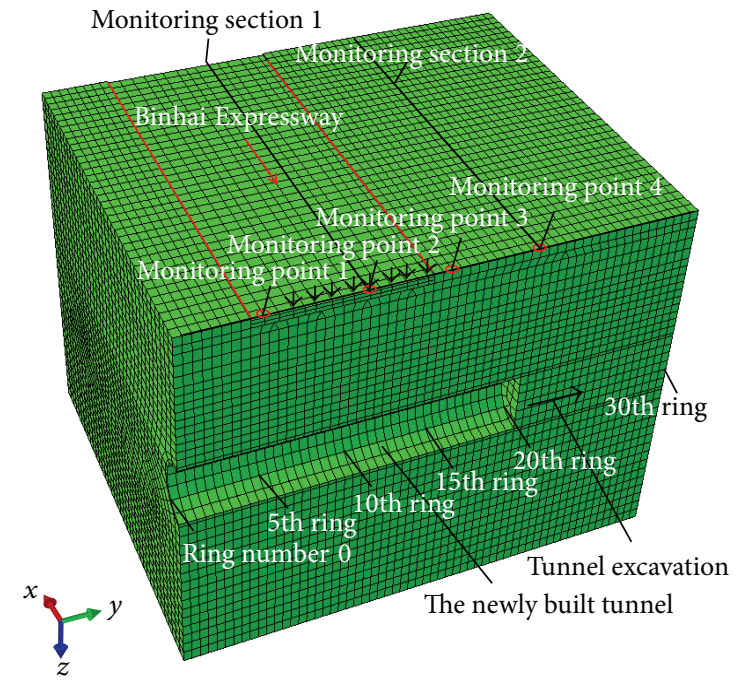

(a)

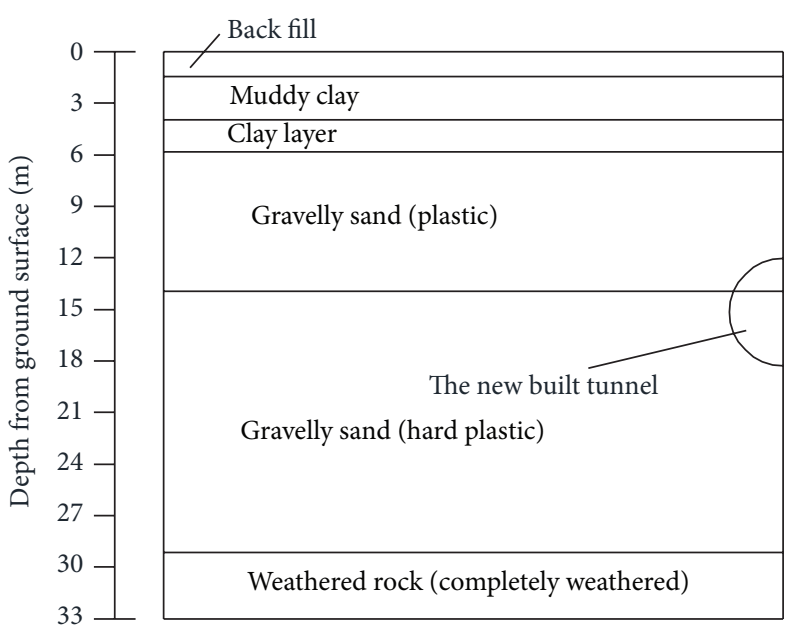

(b)

Figure 3: 3D finite element model.

of the working site can be divided into two types: loose soil pore water and bedrock fissure water. The main occurrence of pore water is consistent with the Quaternary System Holocene series marine layer, which includes gravel sand (containing mud) and a proluvium-alluvium gravel sand layer. The bedrock fissure water originates primarily from the bedrock fracture of strongly weathered rock to mediumweathered rock. The two types of groundwater generally have no pressure but similar penetrations. The groundwater table is in the range of $0.70-64.60 \mathrm{~m}$, and the maximum tunnel inflow rate is $7576 \mathrm{~m}^{3} / \mathrm{d}$. The site belongs to a very rich water area; water inflow and local quicksand are common occurrences. Therefore, the soft soil in the coastal reclamation area is featured by bad water permeability and big water content. To simplify the calculation, our analysis did not consider the impact of the consolidation and creep of clay.

2.3. Characteristics of the Expressway and Vehicles. The total length of the Binhai Expressway within the territory of Shenzhen is $9.8 \mathrm{~km}$, consisting of $610000 \mathrm{~m}^{2}$ subgrade reclamation from Nanshan District to Luohu District. The Binhai Expressway is an eight-lane urban expressway with heavy traffic and frequent congestion in the morning and evening peak hours. The traffic condition can be assessed in terms of annual average daily traffic (AADT). The AADT is more than 600,000 vehicles per day for each traffic direction. The shield tunnel is from ZDK9 892.500 to ZDK10 45.000 mileage beneath Binhai Expressway and passes through the expressway twice (Figure 1). On this section of the expressway, traffic during the evening peak hours is highly congested, and the vehicles move towards the Binhai Expressway with an average speed of $22.12 \mathrm{~km} / \mathrm{h}$, which is much lower than the design speed limit of $80 \mathrm{~km} / \mathrm{h}$. The pavement structure sections [27] are illustrated in Table 1. As it can be seen, the pavement structure from the surface to the base can be divided into four layers in terms of its material type.
TABLE 1: Layer material type and thickness data.

\begin{tabular}{lc}
\hline Layer material type & Thickness $(\mathrm{cm})$ \\
\hline Stone matrix asphalt (SMA-16) & 4 \\
Asphalt concrete (AC-25I) & 8 \\
Asphalt macadam (AM-30) & 8 \\
Cement-stabilized base & 80 \\
\hline
\end{tabular}

\section{3D Finite Element Model (FEM) and Methodology}

3.1. Numerical Tool and Constitutive Models. In the current study, the finite element (FE) analysis package ABAQUS [28] was used in the numerical analyses to study the effects of soil deformation caused by tunneling under vehicle loads in the coastal reclamation area. The soil was simulated using an elastoplastic constitutive relationship based on the MohrCoulomb criterion and the tunnel lining was modeled as an isotropic linear elastic material.

3.2. Calculation Parameters. Table 2 shows the calculation parameters. The model parameters of soil layers in Table 2 are obtained based on geotechnical drilling, in situ data, and laboratory testing of Shenzhen Metro projects [29-32]. The moisture content of the soil has been determined through oven drying method. The compression modulus is obtained from standard penetration test, static penetration test, and pressuremeter test. The internal friction and cohesion of the soil have been determined through standard penetration test, dynamic penetration test, and vane shear test. The Poisson's ratio used in the current study was slightly modified from a previous study by Chen et al. $[29,30,32]$ and Wang et al. [31]. The water pressures and initial stresses are calculated separately. The burial depth of groundwater is $0.70-4.60 \mathrm{~m}$, and the water level elevation is -1.40 to $2.81 \mathrm{~m}$. 
TABLE 2: Input parameters of the soil layers.

\begin{tabular}{|c|c|c|c|c|c|c|}
\hline $\begin{array}{l}\text { Strata } \\
\text { number }\end{array}$ & Strata & $\begin{array}{l}\text { Moisture content } \\
\text { (\%) }\end{array}$ & $\begin{array}{c}\text { Compression } \\
\text { modulus } \\
(\mathrm{MPa})\end{array}$ & $\begin{array}{c}\text { Internal friction } \\
\left({ }^{\circ}\right)\end{array}$ & $\begin{array}{c}\text { Cohesion } \\
(\mathrm{kPa})\end{array}$ & $\begin{array}{c}\text { Poisson's ratio } \\
\qquad(\mu)\end{array}$ \\
\hline (1) & Backfill & & & & & \\
\hline (3) & Muddy clay & 50.9 & 2.5 & 3.5 & 6 & 0.40 \\
\hline (5) & Clay layer & 32.6 & 5.5 & 15 & 25 & 0.28 \\
\hline (8) & Gravelly sand (plastic) & 33.2 & 7.5 & 20 & 22 & 0.29 \\
\hline $8_{3}$ & $\begin{array}{l}\text { Gravelly sand (hard } \\
\text { plastic) }\end{array}$ & 28.4 & 9.5 & 22 & 25 & 0.30 \\
\hline $9_{1}$ & $\begin{array}{l}\text { Weathered rock } \\
\text { (completely weathered) }\end{array}$ & 25.5 & & 24 & 26 & 0.28 \\
\hline
\end{tabular}

The groundwater of the working site mainly is loose soil pore water. The site belongs to a very rich water area. This paper adopts the method of joint calculation of water and earth pressures. Soil bulk density below the groundwater is calculated using the effective unit weight, which is $10 \mathrm{kN} / \mathrm{m}^{3}$ in this numerical analysis. The initial stresses are calculated by means of the $K_{0}$ procedure. The value of $K_{0}$ is based on Jaky's formula: $K_{0}=1-\sin \varphi$, in which $\varphi$ is the effective angle of the internal friction of the host soil [33]. However, it should be noted that the internal friction angles of gravelly sand and rock are too low $\left(20 \sim 24^{\circ}\right)$ for six reasons: mineral composition, grain gradation, original density, water content, structure, and precharge pressure. Because this project is located in coastal reclamation area, the internal friction angle is lower than normal consolidation soil.

3.3. 3D Finite Element Model (FEM). Considering the symmetry of the geometry and loading conditions, only half of the tunnel (Figure 3(a)) is represented in the 3D FEM model. Figure 3(b) shows the soil profile in this study. All relevant components of the construction process, including the treatment of the soil and ground water, tunneling, and tail void grouting, are taken into account as separate components in the model. The effect of tail void injection is modeled by a pressure diagram applied on a 5-meter distance behind the tail [34]. A partial filling of the void due to earth pressure balance shield machine (EPBS) diameter reduction is assumed by taking into account only $25 \%$ of the actual diameter reduction. The calculation range of the model is $36 \mathrm{~m} \times 45 \mathrm{~m}$ $\times 33 \mathrm{~m}$ along the $x, y$, and $z$ axes, respectively. The positive direction of the $y$ axis is the direction of the shield tunneling, while the $z$ axis is in the upward positive and the $x$ axis is in the upward right positive. In this model, the average depth of the tunnel is $16 \mathrm{~m}$ (measured from ground surface to tunnel crown) and the excavation diameter of tunnel is $6.28 \mathrm{~m}$. As indicated by displacement boundary conditions, the upper boundary of the model is considered as a free boundary while the bottom of the tunnel is considered as a fixed boundary of which the horizontal and vertical movements are limited. The shield machine is modeled by a plate element, and the solid elements are assigned for lining with an elastic behavior. All the analyses for tunnel excavation are based on the undrained condition. The finite element mesh includes 82524 eight-node isoparametric hexahedral elements with 88874 nodes. In our study, the goal is to compare the calculated values obtained using $3 \mathrm{D}$ calculations to the experimental ones. So, for the sake of numerical modeling, four critical measurement points (monitoring points 1, 2, 3, and 4) and two critical monitoring sections (monitoring section 1 and monitoring section 2 ) in the tunnel were set (Figure 3(a)). They are located at the ground surface. The monitoring section 1 is located $15 \mathrm{~m}$ from the beginning of the $y$ axes. The monitoring section 2 is located $30 \mathrm{~m}$ from the beginning of the $y$ axes. Monitoring points 1, 2, 3, and 4 are located at the center of tunnel (resp., $7.5 \mathrm{~m}, 15.0 \mathrm{~m}, 22.5 \mathrm{~m}$, and $30.0 \mathrm{~m}$ from the beginning of the $y$ axes). Note that the stress path analysis was performed for each incremental advance of the tunnel face using an iterative solver, as reported by Chen et al. [32]. Therefore, in the numerical analysis, the influence of stress path was ignored. For more on the influence of stress path on tunnel excavation response, please refer to $[32,35]$.

3.4. Vehicle Loads. According to vehicle loads investigations, the vehicle loads of $200 \mathrm{kN}$ and $550 \mathrm{kN}$ have the most significant influence on the soil deformation on Binhai Expressway. Based on the characteristic of vehicle loads and the research results [36-38], vehicle loads are simplified as quasi-static loads which distributed centrally at the places of the axles. The value of the load applied at each axle follows the standard of technical standard of highway engineering (JTG-2003) [39] (Figures 4(a) and 4(b) and Table 3). At the same time, the force of wheels acting on a road is also assumed to be concentrated force (Figures 5(a) and 5(b)). The vehicle loads of $200 \mathrm{kN}$ and $550 \mathrm{kN}$ are adopted for calculation under extreme condition with symmetrical dynamic load; that is, four vehicles act on a calculation section (Figure 6). The rear axle load is adopted to calculate the size of the vehicle loads according to the literatures $[37,38]$.

3.5. Calculation Conditions. To analyze the effect of shield construction on soil deformation in the study site comprehensively while taking the disturbance from long-term cyclic dynamic loading of vehicles on Binhai Expressway into consideration, it is necessary to categorize the tunnel space, buried depth, construction parameters, time, and other 
TABLE 3: Main technical characteristics of vehicle of $200 \mathrm{kN}$ and $550 \mathrm{kN}$.

\begin{tabular}{|c|c|c|c|c|c|}
\hline \multicolumn{6}{|c|}{ Main index } \\
\hline Deadweight $(\mathrm{kN})$ & Front axle $(\mathrm{kN})$ & Medial axle $(\mathrm{kN})$ & Rear axle $(\mathrm{kN})$ & $\begin{array}{l}\text { Width and length } \\
\text { (front wheels }) \\
(\mathrm{m} \times \mathrm{m})\end{array}$ & $\begin{array}{c}\text { Width and length } \\
\text { (medial, rear wheels) } \\
(\mathrm{m} \times \mathrm{m})\end{array}$ \\
\hline 200 & 70 & - & 130 & $0.3 \times 0.2$ & $0.6 \times 0.2$ \\
\hline 550 & 30 & 240 & 280 & $0.3 \times 0.2$ & $0.6 \times 0.2$ \\
\hline
\end{tabular}

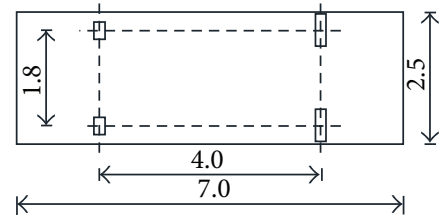

(a) Vehicle load of $200 \mathrm{kN}$

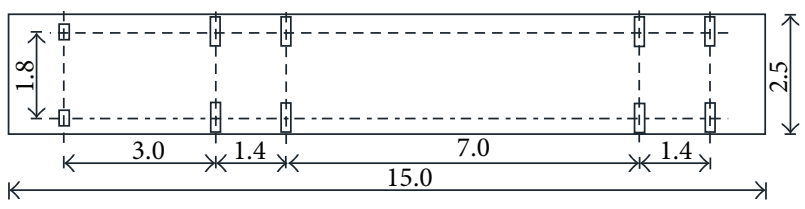

(b) Vehicle load of $550 \mathrm{kN}$

FIgURE 4: Plane dimensions of vehicle (unit: $\mathrm{m}$ ).

factors into two stages for calculation: (1) stage I: the vehicle load is $200 \mathrm{kN}$ during the shield beneath Binhai Expressway; and (2) stage II: the vehicle load is $550 \mathrm{kN}$ during the shield beneath Binhai Expressway. The simulation and calculation of each vertical excavation were implemented with an interval of 1-segment rings for a group, after which comparative analysis of the two stages was conducted.

3.6. Excavation Construction Procedure. The numerical simulation has been carried out by modeling the excavation of $45 \mathrm{~m}$ of tunnel, following a model change method $(1.5 \mathrm{~m}$ per step) [28]. The excavation and installation of the liner are modeled in four analysis steps; that is, the initial stress state is applied and the liner elements are removed, the tunnel excavation begins by reducing the concentrated loads on the tunnel surface, the loads are reduced by $25 \%$ in this step, and after that the liner is installed, and then the surface load is applied, and the excavation is completed by removing the remainder of the load on the tunnel perimeter. Such a simplified modeling approach adopted in the current study was based on a previous study by Yoo [2], Li et al. [40], Wong et al. [41], and Wang et al. [31]. The tunneling process, consisting of a series of excavation and shotcrete lining installation stages, was closely followed by removing and adding corresponding elements at designated steps assuming full face excavation with an advance length of $1.5 \mathrm{~m}$. In the numerical analysis, a constant pressure which equals the atrest earth pressure at the centre of tunnel face was assumed following Wong et al. [41] and Yoo [2]. The tunnel excavation was then simulated in 30 steps.

\section{Results and Discussions}

Four critical measurement points and two critical monitoring sections in the tunnel were set: shield tunneling at 5th, 10th, 15th, and 20th rings (Figure 3(a)). To illustrate soil deformation, we take monitoring section 1 as an example.

4.1. Analysis of Transverse Settlement. The transverse settlement distances curves of stages I and II in the shield beneath Binhai Expressway are shown in Figures 7 and 8 and Table 4. The maximum soil deformation occurs near the longitudinal medial axis of the tunnel, whereas the minimum cumulative settlement occurs at a distance away from the farthest point of the midline. The settlement is mainly distributed within the area of four times of the tunnel diameter, and the shape of the settlement curve is highly similar to the normal distribution curve. The results indicate that the closer the distance from tunnel face, the greater the disturbance from vehicle load and tunnel excavation to the soil deformation of stratum.

The areas affected by soil deformation can be divided into four disturbed zones, namely, the key disturbed zone, the secondary disturbed zone, the general disturbed zone, and the minor-disturbed zone. The definitions of the key disturbed zone, the secondary disturbed zone, the general disturbed zone, are the minor-disturbed zone are the property of the soft soil which allows it to produce deformation and breakage within 4 meters, 4 to 10 meters, 10 to 25 meters, and 25 to 36 meters from the tunnel centerline (settlement trough width), respectively, under the interaction of shield tunneling and vehicle loads. The locations of these four zones are $4 \mathrm{~m}, 4-10 \mathrm{~m}, 10-25 \mathrm{~m}$, and 25-36 $\mathrm{m}$ away from the lateral midline of the tunnel, respectively. Among the four zones, the key disturbed zone, which exhibits disturbance of soil above the tunnel, is affected by shield construction most remarkably. Table 4 shows the soil deformation of the shield beneath Binhai Expressway, in which the vehicle load $550 \mathrm{kN}$ exhibits more substantial deformation than the $200 \mathrm{kN}$ does. The maximum soil deformations are $-16.21 \mathrm{~mm},-6.36 \mathrm{~mm}$, $+1.72 \mathrm{~mm}$, and $+1.07 \mathrm{~mm}$ for the key disturbed zone, secondary disturbed zone, general disturbed zone, and minordisturbed zone, respectively. The soil layer in the coastal reclamation area is loose. The shield beneath Binhai Expressway passes mainly through a sandy (gravel) cohesive soil layer which has good permeability and abundant water. As the layer has unevenly thickness and poor self-stability, it is easy to lose its strength when affected by groundwater. During the initial shield construction, time, excessively large established 


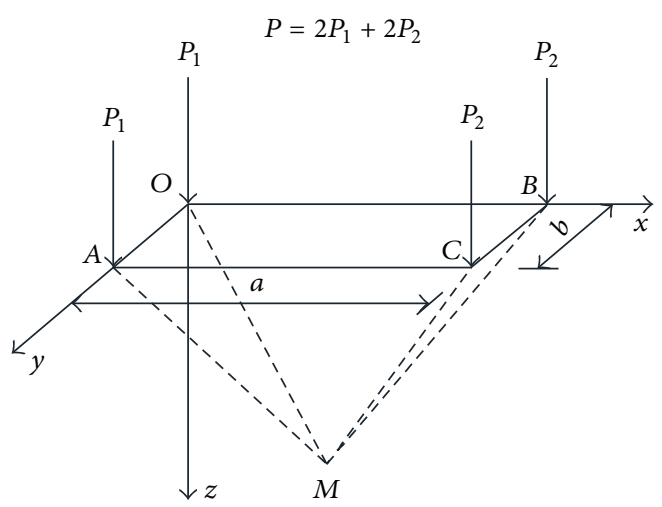

(a) Vehicle load of $200 \mathrm{kN}$

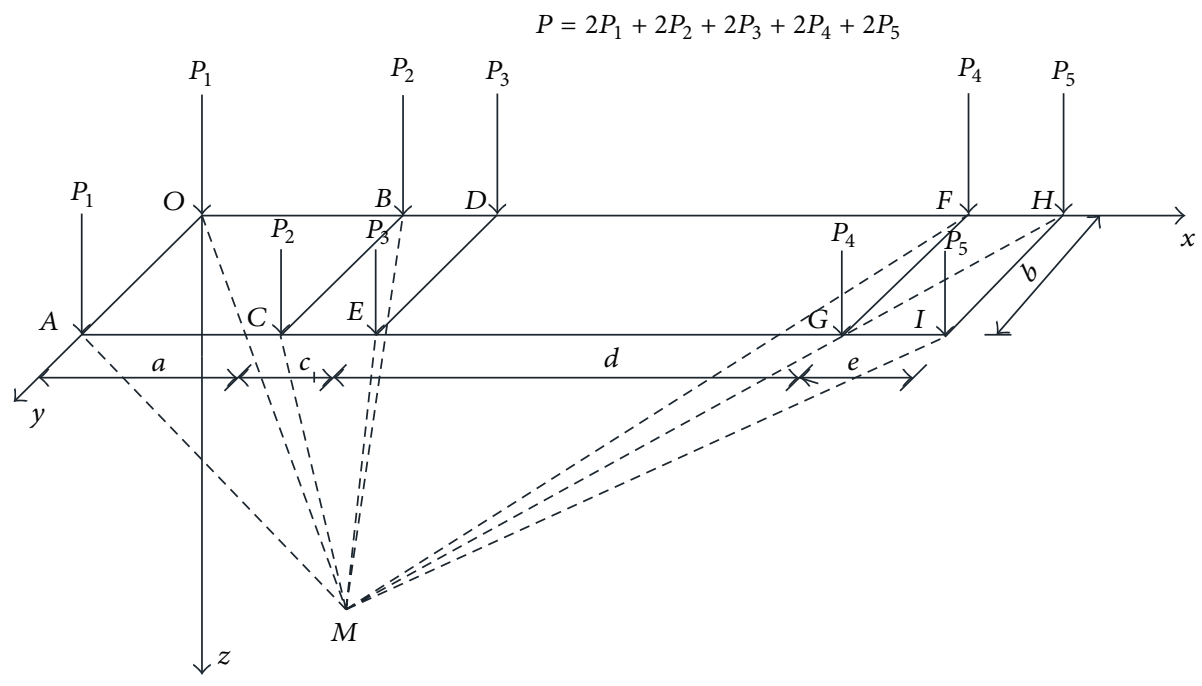

(b) Vehicle load of $550 \mathrm{kN}$

FIGURE 5: Sketch of the distribution of vehicle loads.

TABLE 4: Simulated soil deformations.

\begin{tabular}{lccc}
\hline Soil deformation division & Disturbed area $(\mathrm{m})$ & \multicolumn{2}{c}{$\begin{array}{c}\text { Transverse settlement } \\
\text { Disturbance value (mm) }\end{array}$} \\
\hline Key disturbed zone & & Vehicle load 550 kN & -7.6 to -3.3 \\
Secondary disturbed zone & $0-4$ & -16.21 to -7.86 & -2.68 to +1.13 \\
General disturbed zone & $4-10$ & -6.36 to +0.21 & +1.97 to +0.17 \\
Minor-disturbed zone & $10-25$ & -0.47 to +1.72 & +1.07 to +0.22 \\
\hline
\end{tabular}

earth pressure, grouting volume, grouting pressure, longterm loading of ground vehicles, and other factors will impose a considerable effect on original formation and stress field and cause the stress redistribution across the tunnel. Therefore, strict controlling of the earth pressure, driving speed, grouting pressure, grouting volume, and tunneling direction is recommended. The tunnel excavation shows that the vehicle loads have influences on soil deformation, as reported by Wang et al. [31]. The original structure and the state of limit equilibrium of soil are completely destructed during tunneling. The stress distribution around the tunnel was changed due to tunnel construction. But the soft soil in the coastal reclamation area is characterized by high sensitivity, high water content, and high changeability. Tunneling in the coastal reclamation area is very difficult, because the soft soil' self-stability is very poor. The uplifts of the ground surface have occurred due to the effect of excavation unloading, the friction between the shield shell and soil mass, and the effective synchronous grouting. However, the flexural deflection of road has occurred under vehicle loads, and it is a tensile stress upwards component, with the properties uploading, counteracting the effects of partial vehicle load. Then, the downwards components of pressure stress with the properties loading have prevented the uplifts of the 


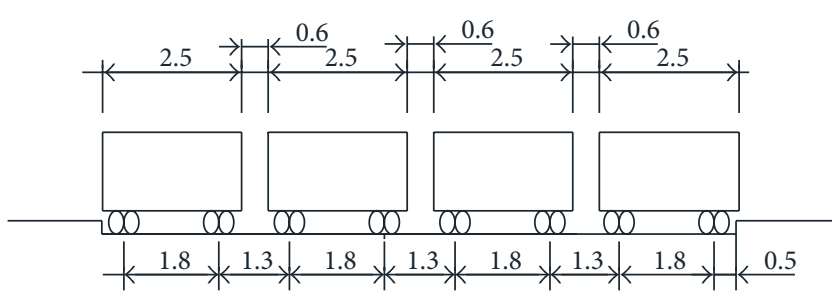

FIGURE 6: Cross arrangement of vehicle (unit: $\mathrm{m}$ ).

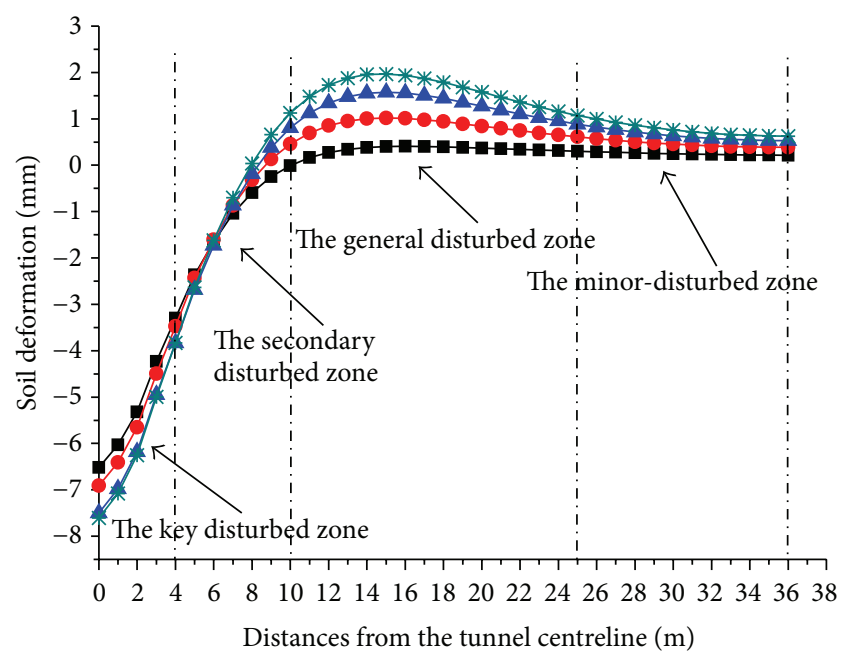

$\rightarrow$ - Shield tunneling to 5 th ring

$\rightarrow$ Shield tunneling to 10 th ring

- - Shield tunneling to 15 th ring

* Shield tunneling to 20th ring

FIgURE 7: Transverse settlement of monitoring section 1 during shield tunneling (stage I).

soil. The effect of vehicle loading is more significant than that of excavation which is affected synthetically by loading, uploading of vehicle loads, and tunnel excavation.

4.2. Analysis of Longitudinal Settlement. The longitudinal settlements of stages I and II are shown in Figures 9 and 10. As it can be seen, the soil deformation in the action zone of vehicle load is greater than that of the nonaction zone of vehicle load. With the increase of vehicle loads, the soil deformation increases gradually. The maximum soil deformations of stage I are $-6.52 \mathrm{~mm},-6.93 \mathrm{~mm},-7.5 \mathrm{~mm}$, and $-7.6 \mathrm{~mm}$ for the shield tunneling at $5 \mathrm{th}, 10 \mathrm{th}, 15 \mathrm{th}, 20 \mathrm{th}$ rings, respectively. The maximum soil deformations of stage II are $-14.81 \mathrm{~mm},-15.34 \mathrm{~mm},-16.05 \mathrm{~mm}$, and $-16.21 \mathrm{~mm}$ for the shield tunneling at 5 th, 10 th, 15 th, and 20 th rings, respectively.

\section{Comparison between the Numerical Predictions and Experimental Results}

5.1. Shield Construction Monitoring. To verify the accuracy of the finite element simulation results, two-point settlement observation sections were placed in the tunnel. In this case, we established a shield tunneling to 10th, 20th ring and selected the shield tunneling to 10th ring sections from the

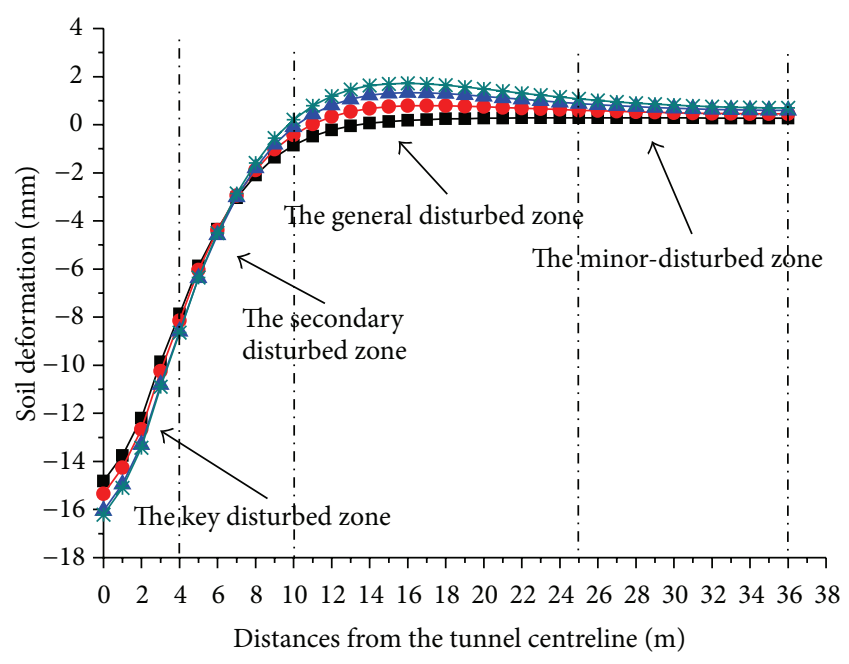

Shield tunneling to 5 th ring

- Shield tunneling to 15 th ring

Shield tunneling to 10 th ring $\quad *$ Shield tunneling to 20 th ring

FIgURE 8: Transverse settlement of monitoring section 1 during shield tunneling (stage II).

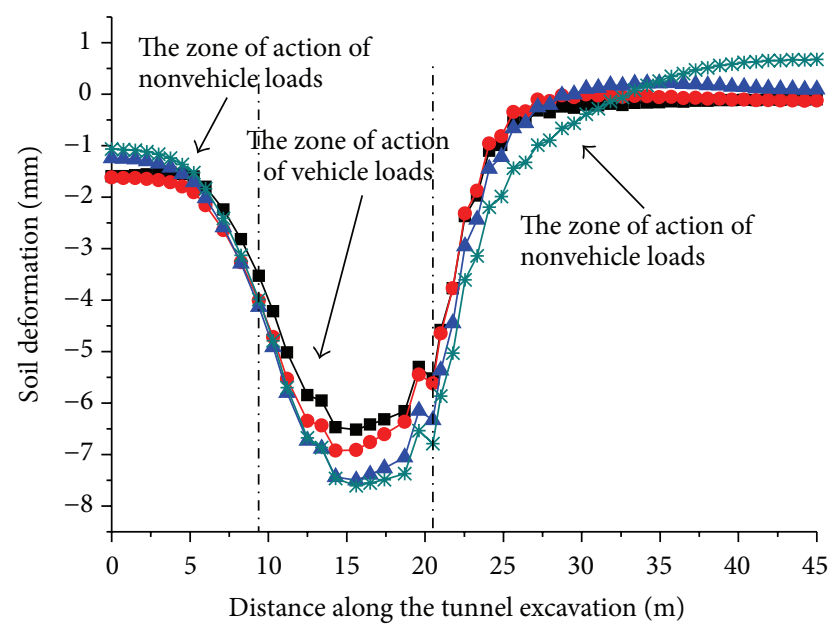

Shield tunneling to 5 th ring _ـ Shield tunneling to 15 th ring Shield tunneling to 10th ring $\quad *$ Shield tunneling to 20th ring

FIGURE 9: Trough profile of longitudinal settlement above the tunnel centerline (stage I).

five observation sections for monitoring (Figure 11). A settlement measurement point and a cross-section measurement point were designed along the longitudinal line of the ground every $5 \mathrm{~m}$ and $30 \mathrm{~m}$ along the advancing direction of the shield, respectively.

5.2. Comparative Analysis of Transverse Deformation. The curves of the soil deformation durations (shield beneath Binhai Expressway) for stages I and II are shown in Figure 12. The comparative analysis indicates that the following.

(1) The soil deformation of the shield beneath Binhai Expressway in stage II is larger than that observed in stage I, indicating the complex geology of the coastal 


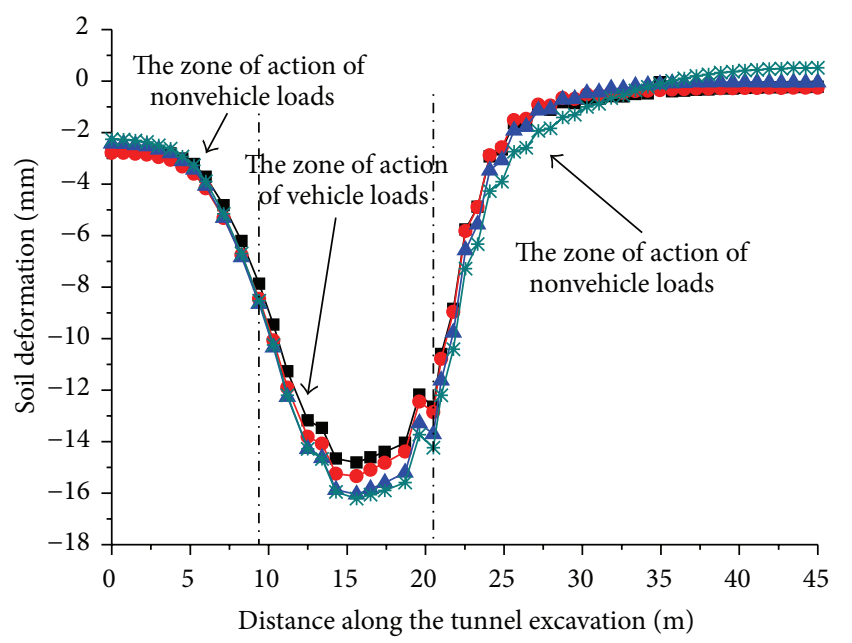

$\rightarrow$ Shield tunneling to 5 th ring _ $\quad$ - Shield tunneling to 15 th ring Shield tunneling to 10th ring $\quad$ - Shield tunneling to 20th ring

Figure 10: Trough profile of longitudinal settlement above the tunnel centerline (stage II).

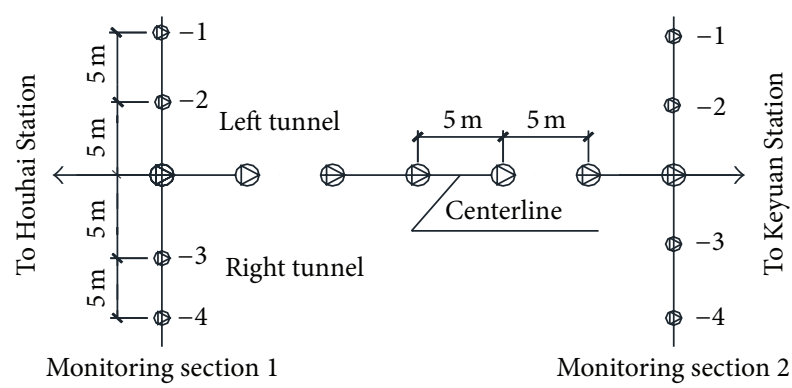

FIGURE 11: Layout of the measurement points.

reclamation area. The calculation conditions of construction, changes of the original formation and stress filed, and excavation stress impose a strong effect on soil deformation. The cumulative maximum soil deformation occurs at the longitudinal medial axis of the tunnel, whereas the minimum cumulative settlement is observed at a distance away from the farthest point of the midline. Compared with the observed data between stage I and stage II, the simulated results fit well with the field observation. At monitoring section 1, the maximum simulated cumulative settlement for the stage II is $-15.34 \mathrm{~mm}$ while the maximum and the minimum monitoring cumulative settlements are $-12.68 \mathrm{~mm}$ and $-0.29 \mathrm{~mm}$, respectively. This is because the tunnel width is small, and the formation is characterized primarily by sandy (gravel) cohesive soil $88_{2}, 8_{3}$. The soil exhibits plasticity to low plasticity and comprises $10 \%-30 \%$ gravel volume. A large boulder group formed in the prophase sea reclamation exists on top of the tunnel. The rubble has a large diameter (Figure 13), which will possibly reduce driving speed, slow down cutter rotational speed, and increase thrust in shield construction.

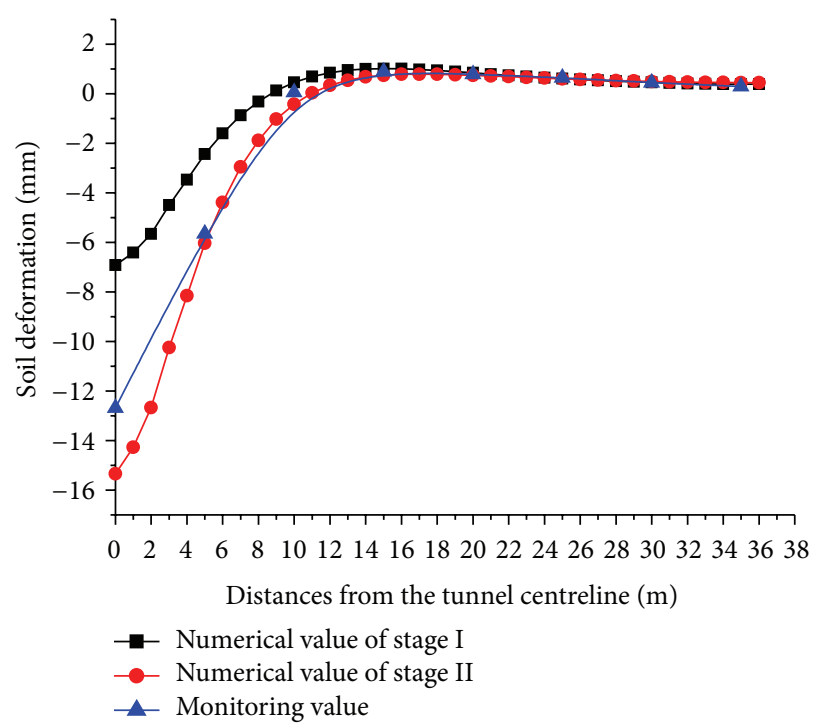

FIGURE 12: Comparison of transverse settlements of monitoring section 1 during shield tunneling.

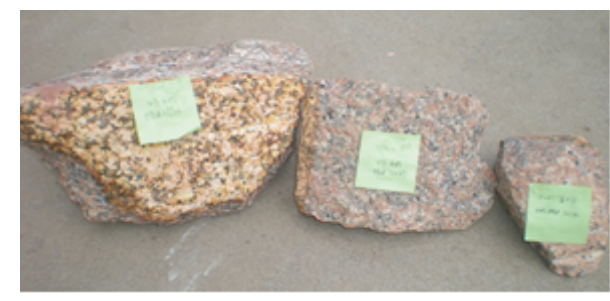

Figure 13: Samples of rubble.

Therefore, the comprehensive analysis for controlling soil deformation should consider prediction and monitoring data.

(2) Ground settlement is distributed in the diameter zone with a fourfold diameter. The centerline of this zone is the symmetrical axis. The key ground settlement occurs above the tunnel, which is the secondary ground settlement zone, with a 0.5-2.6 times diameter, on the centerline of the tunnel. The minor-ground settlement zone is beyond the 4 times diameter and can be disregarded. This conclusion is consistent with the prediction result on soil deformation.

5.3. Comparative Analysis of Longitudinal Deformation. Figure 14 shows the cumulative settlements of the longitudinal of stages I and II in the shield beneath Binhai Expressway. The comparative analysis indicates the following.

(1) The overall control of the surface settlement caused by the tunnel is good, indicating that controlling soil deformation on the basis of the FE analysis and site monitoring is a reasonable approach. The maximum cumulative surface settlement of stage $I$ is $-6.93 \mathrm{~mm}$, located at $14.3 \mathrm{~m}$ away from the ring number 0 , whereas the minimum settlement is $-0.12 \mathrm{~mm}$, located at $45 \mathrm{~m}$ way from the ring number 0 . The 


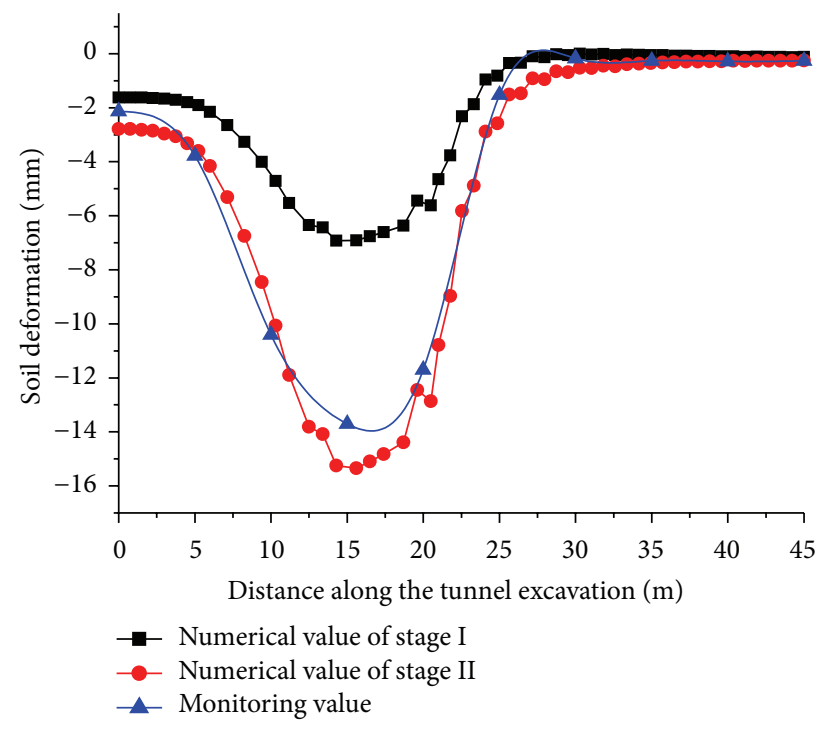

Figure 14: Comparison of longitudinal settlement during shield tunneling along the tunnel excavation.

surface settlement of stage II is larger than that of stage I. The ground settlement reaches $-15.34 \mathrm{~mm}$, especially before the shield beneath Binhai Expressway. However, this issue is effectively controlled after using a reasonable control technology. The average settlement of the action zone of vehicle loads is $-13.21 \mathrm{~mm}$. These results can be used to forecast the soil deformation and accordingly a measurement for shield construction control can be proposed. In this measurement, an accurate earth pressure is selected, driving speed, mixed proportions of grouting material, and the amount of oil in the shield tail are controlled, monitoring and measurement are strengthened, and information management is implemented. The overall control of surface settlement ensures construction security and tunnel stability. It also reflects the importance of the prediction model ABAQUS.

(2) Disturbance from the long-term cyclic dynamic loading of vehicles on Binhai Expressway and the Binhai Expressway overpass near the tunnel also influence soil deformation. The mileage of 9.3 to $20.5 \mathrm{~m}$ is located below the main carriageway of Binhai Expressway. The cumulative settlement is large; the maximum is $-15.34 \mathrm{~mm}$; and the minimum is $-8.46 \mathrm{~mm}$. This result indicates the positive effect of controlling surface settlement.

\section{Conclusions}

In this paper, 3D ABAQUS is adopted to simulate the soil deformation due to tunneling under vehicle loads in the coastal reclamation area. A field case study was also carried out to verify the FEM model. A good agreement between the numerical results and the experimental results was achieved. Other main conclusions derived from the study are summarized as follows.

(1) The areas affected by soil deformation can be classified into the key disturbed zone, the secondary disturbed zone, the general disturbed zone, and the minordisturbed zone. Among the four zones, the key disturbed zone that exhibits disturbance of the soil above the tunnel is affected most remarkably by the soil deformation under tunneling. The four zones are located at $4 \mathrm{~m}, 4-10 \mathrm{~m}, 10-25 \mathrm{~m}$, and $25-36 \mathrm{~m}$ away from the midline of tunnel along the lateral direction, respectively.

(2) The maximum soil deformation occurs near the longitudinal medial axis of the tunnel, whereas the minimum cumulative settlement occurs at the farthest point of the midline. The settlement distributed in a range of four times of the tunnel diameter and the shape of the settlement curve is highly similar to the normal distribution curve.

(3) The soil deformation in the action zone of vehicle load is greater than that of the nonaction zone of vehicle load. The closer the distance from the tunnel face, the greater the disturbance from vehicle load and tunnel excavation to the soil deformation.

In the numerical analysis, the interaction of vehicle loads, road, soil, and tunnel was not considered. In addition, the influence of strut installation was ignored to simplify the problem. In the future, the effects of additional factors and other affecting parameters, such as vehicle types, vehicle frequencies, the distribution pattern of the vehicle loads, and the rheological behavior of the soft soil on the distribution and the magnitude of soil deformation under shield construction, are suggested to be studied through numerical methods, theoretical analysis, and the physical models.

\section{Conflict of Interests}

The authors declare that there is no conflict of interests regarding the publication of this paper.

\section{Acknowledgments}

The financial supports for this research project by the National Natural Science Foundation of China (no. 41072205), the Foundation of Zhejiang University of Science and Technology (no. F702104E03 and no. F703104D01), the Program for New Century Excellent Talents in University (no. NCET-11-1080), the first level talent of "151 Talents Project" in Zhejiang Province (no. 12-1-076), the Natural Science Foundation of Zhejiang Province, China (no. LQ13D020001), and the Foundation of China Railway No. 2 Engineering Group Co. Ltd. (no. 201218) are all gratefully acknowledged. The authors wish to thank Professor Zhao Zhiye of the School of Civil and Environmental Engineering, Nanyang Technological University (NTU), for his kind suggestion and the discussions on the relevant topics of this research work. The authors are grateful to Dr. Nie Wen, Dr. He Lei, 
Dr. An Xinmei, and Mr. Xu Zhipeng from NTU and Dr. Yang Dong from Tongji University for providing useful information and discussion in this paper.

\section{References}

[1] H. Y. Liu, J. C. Small, and J. P. Carter, "Full 3D modelling for effects of tunnelling on existing support systems in the Sydney region," Tunnelling and Underground Space Technology, vol. 23, no. 4, pp. 399-420, 2008.

[2] C. Yoo, "Interaction between tunneling and bridge foundation-a 3D numerical investigation," Computers and Geotechnics, vol. 49, pp. 70-78, 2013.

[3] N. Bobylev, "Comparative analysis of environmental impacts of selected underground construction technologies using the analytic network process," Automation in Construction, vol. 20, no. 8, pp. 1030-1040, 2011.

[4] T. B. Celestino, R. A. M. P. Gomes, and A. A. Bortolucci, "Errors in ground distortions due to settlement trough adjustment," Tunnelling and Underground Space Technology, vol. 15, no. 1, pp. 97-100, 2000.

[5] P. B. Attewell and M. R. Hurrell, "Settlement development caused by tunnelling in soil," Ground Engineering, vol. 18, no. 8, pp. 17-20, 1985.

[6] M. P. O'Reilly and B. M. New, "Settlements above tunnels in the United Kingdom, their magnitude and prediction," in Proceedings of the Tunnelling Symposium, pp. 173-181, Brighton, UK, 1982.

[7] R. B. Peck, "Deep excavations and tunnelling in soft ground," in Proceeding of the 7th International Conference on Soil Mechanics and Foundation Engineering, pp. 225-290, Mexico City, Mexico, 1969.

[8] M. Karakus, "Appraising the methods accounting for 3D tunnelling effects in 2D plane strain FE analysis," Tunnelling and Underground Space Technology, vol. 22, no. 1, pp. 47-56, 2007.

[9] M. Karakus and R. J. Fowell, "Back analysis for tunnelling induced ground movements and stress redistribution," Tunnelling and Underground Space Technology, vol. 20, no. 6, pp. 514-524, 2005.

[10] W.-I. Chou and A. Bobet, "Predictions of ground deformations in shallow tunnels in clay," Tunnelling and Underground Space Technology, vol. 17, no. 1, pp. 3-19, 2002.

[11] C. Sagaseta, "Analysis of undrained soil deformation due to ground loss," Geotechnique, vol. 37, no. 3, pp. 301-320, 1987.

[12] A. Juneja, A. Hegde, F. H. Lee, and C. H. Yeo, "Centrifuge modelling of tunnel face reinforcement using forepoling," Tunnelling and Underground Space Technology, vol. 25, no. 4, pp. 377-381, 2010.

[13] J. S. Sharma, M. D. Bolton, and R. E. Boyle, "A new technique for simulation of tunnel excavation in a centrifuge," Geotechnical Testing Journal, vol. 24, no. 4, pp. 343-349, 2001.

[14] O. J. Santos Jr. and T. B. Celestino, "Artificial neural networks analysis of São Paulo subway tunnel settlement data," Tunnelling and Underground Space Technology, vol. 23, no. 5, pp. 481-491, 2008.

[15] K. M. Neaupane and N. R. Adhikari, "Prediction of tunnelinginduced ground movement with the multi-layer perceptron," Tunnelling and Underground Space Technology, vol. 21, no. 2, pp. 151-159, 2006.

[16] J. Sun and J. R. Yuan, "Soil disturbance and ground movement under shield tunnelling and its intelligent prediction by using
ANN technology," Chinese Journal of Geotechnical Engineering, vol. 23, no. 3, pp. 261-267, 2001.

[17] C. Y. Kim, G. J. Bae, S. W. Hong, C. H. Park, H. K. Moon, and H. S. Shin, "Neural network based prediction of ground surface settlements due to tunnelling," Computers and Geotechnics, vol. 28, no. 6-7, pp. 517-547, 2001.

[18] S.-S. Leu, C.-N. Chen, and S.-L. Chang, "Data mining for tunnel support stability: neural network approach," Automation in Construction, vol. 10, no. 4, pp. 429-441, 2001.

[19] L. Ma, H. B. Luo, and H. R. Chen, "Safety risk analysis based on a geotechnical instrumentation data warehouse in metro tunnel project," Automation in Construction, vol. 34, pp. 75-84, 2013.

[20] M. Migliazza, M. Chiorboli, and G. P. Giani, "Comparison of analytical method, 3D finite element model with experimental subsidence measurements resulting from the extension of the Milan underground," Computers and Geotechnics, vol. 36, no. 12, pp. 113-124, 2009.

[21] G. T. K. Lee and C. W. W. Ng, "Effects of advancing open face tunneling on an existing loaded pile," Journal of Geotechnical and Geoenvironmental Engineering, vol. 131, no. 2, pp. 193-201, 2005.

[22] J. N. Franzius, D. M. Potts, and J. B. Burland, "The influence of soil anisotropy and Ko on ground surface movements resulting from tunnel excavation," Geotechnique, vol. 55, no. 3, pp. 189199, 2005.

[23] J. H. Shin, T. I. Addenbrooke, and D. M. Potts, "A numerical study of the effect of groundwater movement on long-term tunnel behaviour," Geotechnique, vol. 52, no. 6, pp. 391-403, 2002.

[24] T. I. Addenbrooke, D. M. Potts, and A. M. Puzrin, "The influence of pre-failure soil stiffness on the numerical analysis of tunnel construction," Geotechnique, vol. 47, no. 3, pp. 693-712, 1997.

[25] X. Hu, Y. Huang, Z. Yin, and Y. Xiong, "Optimization-based model of tunneling-induced distributed loads acting on the shield periphery," Automation in Construction, vol. 24, pp. 138148, 2012.

[26] L. Truong-Hong and D. F. Laefer, "Impact of modeling architectural detailing for predicting unreinforced masonry response to subsidence," Automation in Construction, vol. 30, pp. 191-204, 2013.

[27] G. Hu and G. Zhou, "SMA pavement construction technique of Binhai expressway in Shenzhen," Guangdong Highway Communications, no. 2, pp. 36-38, 2003 (Chinese).

[28] ABAQUS, ABAQUS/Standard User's Manual, Hibbitt, Karlsson and Sorensen, 2001.

[29] X. Chen, B. Zou, J. Yi, G. Kuang, and X. Sun, "Ground subsidence monitoring and control in shield tunnel beneath binhai thoroughfare," Journal of Guilin University of Technology, vol. 30, no. 4, pp. 545-550, 2010 (Chinese).

[30] X. Chen, B. Zou, J. Yi, and G. Kuang, "Soil reinforcement technology for water-soaked soft stratum at shield tunnel launching portal," Modern Tunnelling Technology, vol. 47, no. 4, pp. 73-79, 2010 (Chinese).

[31] J. Wang, B. Zou, X. Chen, J. Yi, and G. Kuang, "Numerical simulation of settlement laws of stratum induced by metro shield tunnel under passing highway in sea reclamation area," China Railway Science, vol. 34, no. 4, pp. 33-39, 2013.

[32] X. Chen, B. Zou, J. Yi, R. Mu, and J. Liu, "Analysis on soil displacement and distribution of ground displacement field of shielding tunnel under the BinHai thorough fare of Shenzhen," in Proceedings of the International Conference on Electric 
Technology and Civil Engineering (ICETCE '11), pp. 5745-5749, Lushan, China, April 2011.

[33] Z. X. Zhang, H. Zhang, and J. Y. Yan, "A case study on the behavior of shield tunneling in sandy cobble ground," Environmental Earth Sciences, vol. 69, no. 6, pp. 1891-1900, 2013.

[34] D. Dias and R. Kastner, "Movements caused by the excavation of tunnels using face pressurized shields-analysis of monitoring and numerical modeling results," Engineering Geology, vol. 152, pp. 17-25, 2013.

[35] M. Cai, "Influence of stress path on tunnel excavation response-numerical tool selection and modeling strategy," Tunnelling and Underground Space Technology, vol. 23, no. 6, pp. 618-628, 2008.

[36] S.-C. Wu, A.-B. Jin, and J.-A. Wang, "Numerical simulation of failure mechanism of subgrade retaining structure under vehicle load," Rock and Soil Mechanics, vol. 28, no. 2, pp. 258262, 2007 (Chinese).

[37] X. Wei and M.-S. Huang, "A simple method to predict trafficload-induced permanent settlement of road on soft subsoil," Rock and Soil Mechanics, vol. 30, no. 11, pp. 3342-3346, 2009 (Chinese).

[38] Y.-F. Gao, B. Li, and H.-L. Liu, "Study on quasi-static settlement computation method of highway in soft ground induced by vehicle loads," Chinese Journal of Rock Mechanics and Engineering, vol. 24, no. 2, pp. 5470-5477, 2005 (Chinese).

[39] MOT, Technical Standard of Highway Engineering, China Communication Press, 2003, (Chinese).

[40] Y. Li, F. Emeriault, R. Kastner, and Z. X. Zhang, "Stability analysis of large slurry shield-driven tunnel in soft clay," Tunnelling and Underground Space Technology, vol. 24, no. 4, pp. 472-481, 2009.

[41] K. S. Wong, C. W. W. Ng, Y. M. Chen, and X. C. Bian, "Centrifuge and numerical investigation of passive failure of tunnel face in sand," Tunnelling and Underground Space Technology, vol. 28, no. 1, pp. 297-303, 2012. 


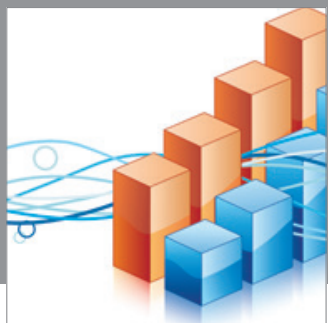

Advances in

Operations Research

mansans

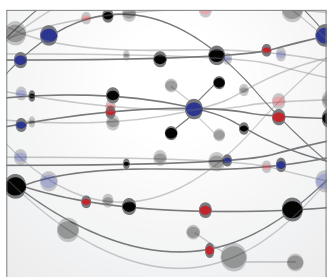

The Scientific World Journal
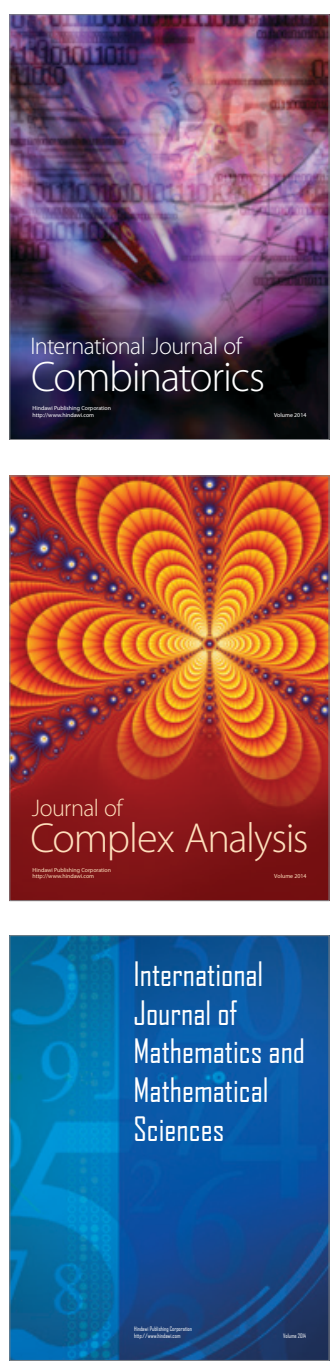
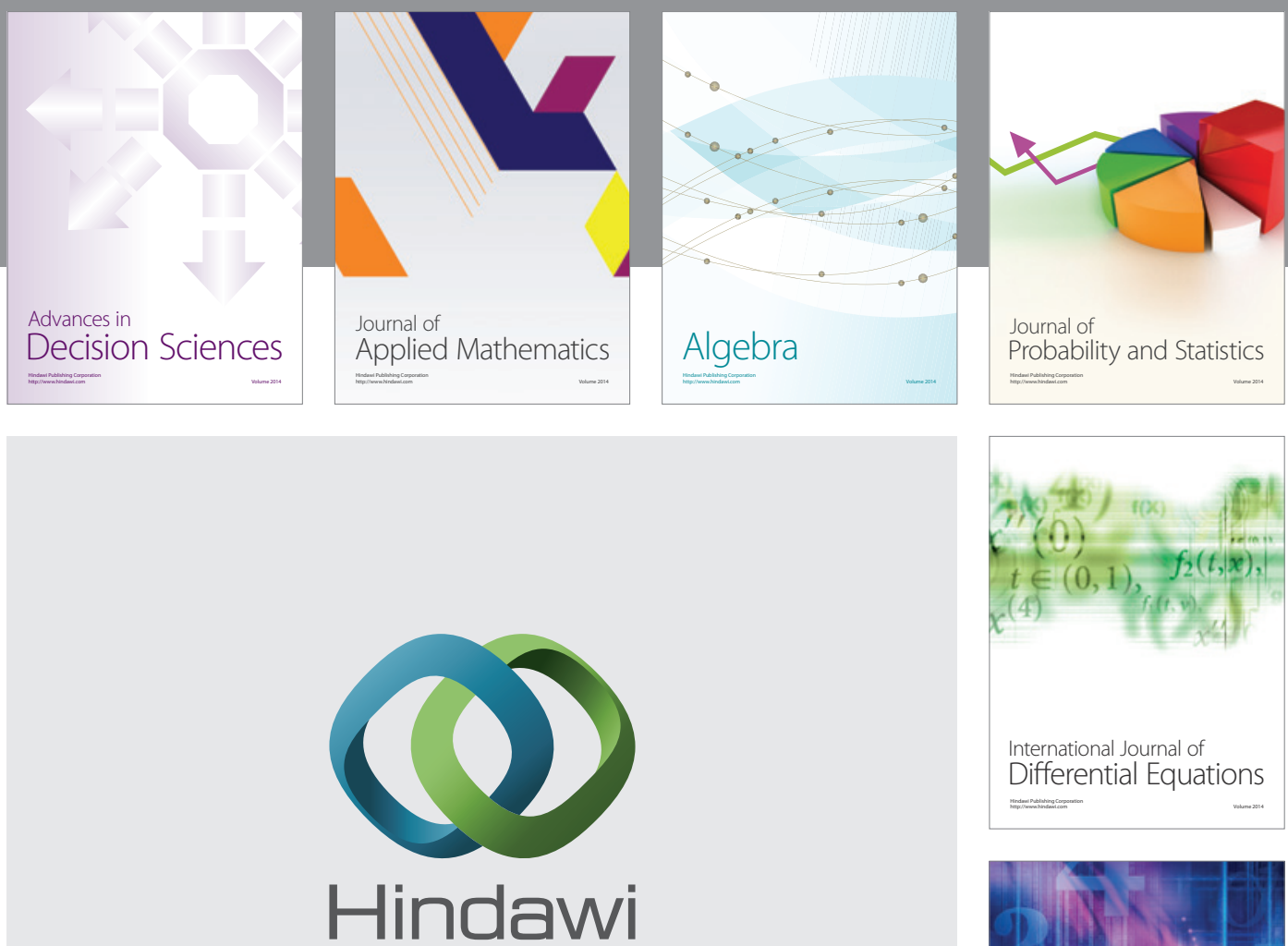

Submit your manuscripts at http://www.hindawi.com
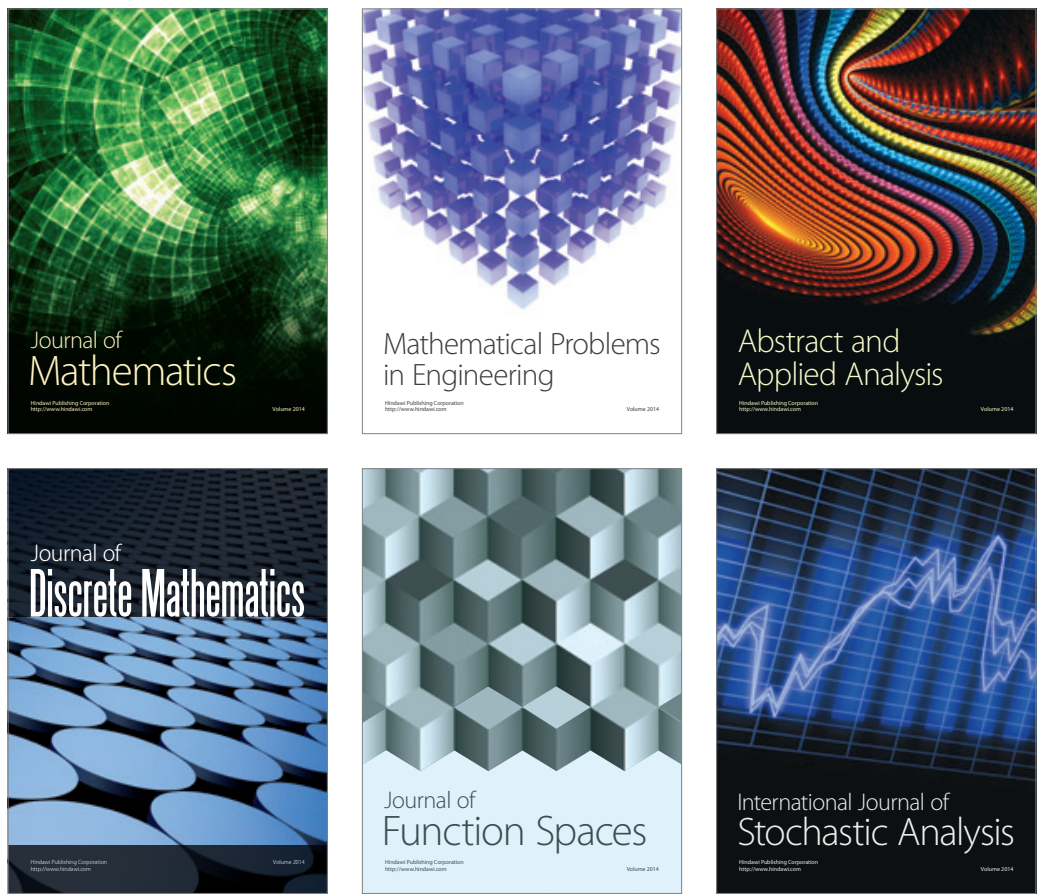

Journal of

Function Spaces

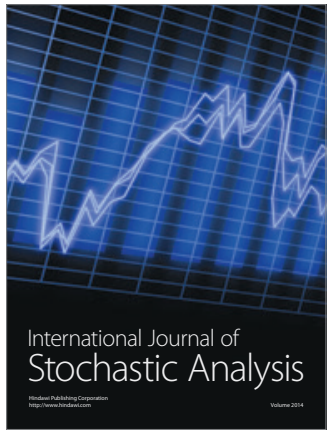

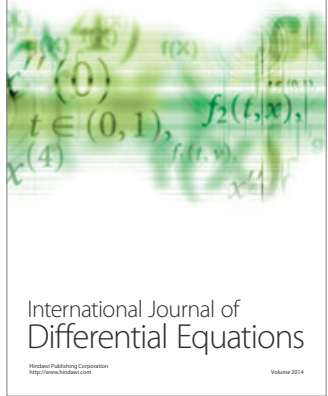
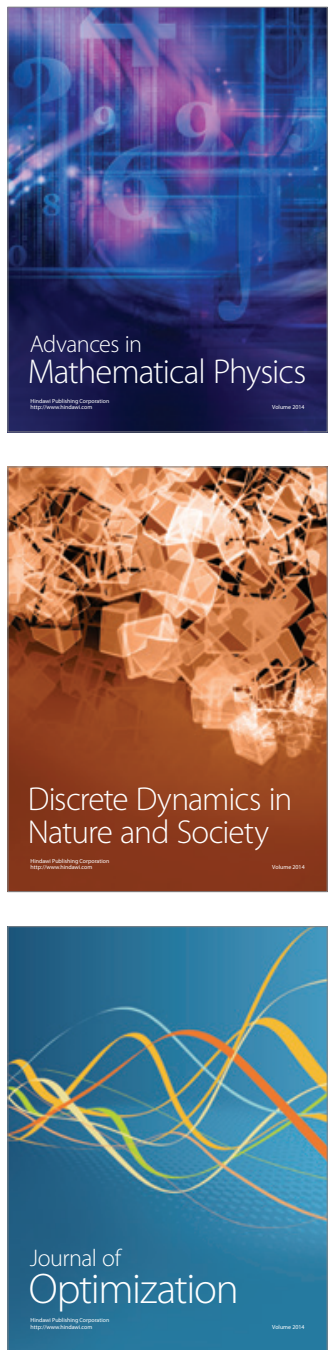